\title{
OPEN Mapping the genetic basis of diabetes mellitus in the Australian Burmese cat (Felis catus)
}

Georgina Samaha ${ }^{1 凶}$, Claire M. Wade ${ }^{2}$, Julia Beatty ${ }^{1,3}$, Leslie A. Lyons ${ }^{4}$, Linda M. Fleeman ${ }^{5}$ \& Bianca Haase $^{1}$

Diabetes mellitus, a common endocrinopathy affecting domestic cats, shares many clinical and pathologic features with type 2 diabetes in humans. In Australia and Europe, diabetes mellitus is almost four times more common among Burmese cats than in other breeds. As a genetically isolated population, the diabetic Australian Burmese cat provides a spontaneous genetic model for studying diabetes mellitus in humans. Studying complex diseases in pedigreed breeds facilitates tighter control of confounding factors including population stratification, allelic frequencies and environmental heterogeneity. We used the feline SNV array and whole genome sequence data to undertake a genome wide-association study and runs of homozygosity analysis, of a case-control cohort of Australian and European Burmese cats. Our results identified diabetes-associated haplotypes across chromosomes A3, B1 and E1 and selective sweeps across the Burmese breed on chromosomes B1, $B 3, D 1$ and D4. The locus on chromosome B1, common to both analyses, revealed coding and splice region variants in candidate genes, $A N K 1, E P H X 2$ and $L O X L 2$, implicated in diabetes mellitus and lipid dysregulation. Mapping this condition in Burmese cats has revealed a polygenic spectrum, implicating loci linked to pancreatic beta cell dysfunction, lipid dysregulation and insulin resistance in the pathogenesis of diabetes mellitus in the Burmese cat.

Domestic cats (Felis catus), a common household pet share with humans many environmental and lifestyle risk factors for metabolic disorders like diabetes mellitus. Feline diabetes mellitus (FDM; OMIA 000277-9685) affects approximately one in 200 cats. Similarities in clinical presentation, pathological findings and risk factors between FDM and human type 2 diabetes (T2D) are well-established ${ }^{1-4}$. Both are characterised by inadequate insulin secretion resulting in absolute or partial insulin deficiency and varying degrees of insulin resistance in peripheral tissues. The prevalence of FDM has been increasing over recent decades, with obesity, diet, over-nutrition and lack of physical inactivity all implicated as risk factors ${ }^{5,6}$. In humans, T2D is known to have a complex underlying genetic architecture, with many genetic risk loci identified by genome wide association studies (GWAS). Such studies have consistently identified T2D associated loci containing genes that alter glucose metabolism or pancreatic $\beta$-cell function ${ }^{7,8}$.

Among recognised cat breeds, the incidence of FDM is highest in Burmese cats ${ }^{9,10}$. In Australia, Britain and Europe, Burmese cats are approximately four times more likely to develop FDM than domestic cats of other breeds or breed mixes ${ }^{11}$. In contrast, the same heightened risk has not been observed in the North American Burmese population which is regarded as genetically distinct ${ }^{12-14}$. Companion animals are increasingly used to model human diseases ${ }^{15,16}$. Studying the basis of diabetes mellitus in the naturally occurring Burmese model circumvents the drawbacks associated with in vivo experimental work involving induced illness in healthy animals and transgenic animals. This includes welfare and the inability to adequately model the disease state ${ }^{17}$. Compared with humans, the relatively short lifespan of cats permits observation of the natural progression of an illness over a compressed timeline.

${ }^{1}$ Faculty of Science, Sydney School of Veterinary Science, University of Sydney, Sydney, NSW, Australia. ${ }^{2}$ School of Life and Environmental Sciences, The University of Sydney, Sydney, NSW, Australia. ${ }^{3}$ Department of Infectious Diseases and Public Health, City University of Hong Kong, Kowloon, Hong Kong SAR, People's Republic of China. ${ }^{4}$ Department of Veterinary Medicine and Surgery, College of Veterinary Medicine, University of Missouri, Columbia, MO, USA. ${ }^{5}$ Animal Diabetes Australia, Melbourne, VIC, Australia. ${ }^{\varpi}$ email: georgina.samaha@ sydney.edu.au 
Breed-specific phenotypes in cats result from selective breeding for desired characteristics such as coat colour and texture, body size and morphology. Breed-specific traits are often accompanied by breed-specific susceptibility to genetic diseases compared with outbred populations. Heritable diseases disproportionately affecting Burmese cats include craniofacial defect ${ }^{18}$, hypokalaemia ${ }^{19}$, hyperlipidaemia ${ }^{20}$, orofacial pain syndrome ${ }^{21}$ and diabetes $^{22}$. Regarding genetic diversity, the Burmese breed has among the lowest levels of heterozygosity, most extensive linkage disequilibrium (LD) and highest inbreeding coefficients in recognised cat breeds ${ }^{14,23}$. This simplified genetic architecture is beneficial for mapping the genetic basis of breed-specific traits. Extensive LD reduces the number of markers required to tag segregating haplotypes ${ }^{23,24}$, making Burmese suitable for analysis on the Illumina Infinium iSelect $63 \mathrm{k}$ Cat DNA genotyping array that is used in this study.

The closed breeding systems used to maintain pedigreed breed lines leave distinct genomic traces, particularly when population bottlenecks, such as the importation of individuals to new countries, create founder effects. The extent and structure of LD varies widely across chromosomes and regions of long-range LD can indicate partial or complete selective sweeps of functional significance in a population. Across species, the process of intensive selection for breed-specific traits influences the frequency, distribution and length of runs of homozygosity $(\mathrm{ROH})^{25}$. ROH exist as long tracts of homozygous genotypes and are often the result of consanguineous matings, but they can arise by other mechanisms ${ }^{25-27}$. Detecting ROH can identify genes that have been subjected to selection in population genetic analyses ${ }^{28,29}$. For example, $\mathrm{ROH}$ detection has been used to map causative recessive variants segregating within human families and canine breeds in complex and Mendelian diseases ${ }^{30-33}$. Enrichment of deleterious variants surrounding regions of selection in domesticated breeds suggest deleterious alleles may 'hitchhike' with nearby positively selected alleles, supporting a link between disease heritability and breed-specific traits ${ }^{33-35}$.

The unique demographic history of the Burmese breed is characterised by reduced effective population sizes, potential founder effects and genetic bottlenecks that may account for differential enrichment of FDM between different breeding populations. In a population with an already reduced genetic diversity, we predict GWAS and ROH analyses offer an opportunity to detect FDM-risk loci segregating in the Australian Burmese breeding population. We used genotyping array and whole genome sequence data to, (1) conduct case-control GWAS of diabetic and non-diabetic Burmese cats, (2) Identify FDM-associated risk haplotypes and (3) perform genome-wide characterisation of Burmese $\mathrm{ROH}$ to expose risk loci that differentiate the heightened prevalence of FDM in this breed.

\section{Results}

Remapping array variants to feline $\mathbf{9 . 0}$ genome assembly. As inconsistencies between genome assemblies can complicate GWAS, the SNV locations of array variants were updated to the most recent feline reference assembly (felCat9). Original locations were included in a manifest provided with the Illumina iSelect 63 Cat DNA genotyping array. For the 62,897 variants on the feline genotyping array, 61,371 (97.6\%) were remapped. This comprised 58,674 autosomal variants and 2697 markers on chromosome X. The marker counts and statistics per chromosome (Table S1a) and the updated map file (Table S1b) are presented in Supplementary data. The largest gap between consecutive markers spanned $82.3 \mathrm{Mb}$ and was detected on chromosome E1. The average distance between markers was $39.7 \mathrm{~kb}$. As expected, gaps and low-density distributions of SNVs were consistently observed flanking centromeres for each chromosome.

Genome-wide and haplotype association analyses. Samples from eighty-two Burmese cats that were genotyped on the Illumina Infinium Feline $63 \mathrm{k}$ iSelect DNA array passed quality control. Multidimensional scaling (MDS) revealed some geographical clustering of cat populations (Fig. 1a). Cats from Europe (EU) clustered distinctly from Australian (AUS) and British (UK) samples. Given geographical clustering of cases, the GWAS was first run in Australian cats only to control for population stratification (analysis 1). Analysis 1 comprised of 22 cases and 20 controls, Cases and controls within the cohort of samples used in the initial case-control GWAS (analysis 1) which were evenly dispersed across the population cohort (herein referred to as the Australian cluster') (Fig. 1b). For analysis 1, the QQ-plot revealed a deviation from the expected $P$-value distribution only in the tail $\left(\lambda=1.03\right.$ ) (Fig. 1c). This analysis totalled 30,212 SNVs and one marker at E2:6,883,182 $\left(\mathrm{P}_{\text {raw }}=4.68 \times 10^{-6}\right)$ passed the empirical genome-wide significance threshold (Fig. 2a).

The 3021 SNVs that comprised the top 10\% associated signals from analysis 1 were run in an expanded cohort of Australian, European and British Burmese cats (22 cases, 60 controls) (analysis 2). SNVs passing genome-wide significance from analysis 2 were observed on chromosomes A3, B1, C2 and E1 (Fig. 2b). The most significantly associated marker from analysis 2 was C2: 139,466,787 $\left(\mathrm{P}_{\text {genome }}=1.26 \times 10^{-5}\right)$. This SNV was found not to be in LD with any surrounding markers and was excluded from further analysis. Additional SNVs passing genomewide significance on chromosomes A3, B1 and E1 were observed within intronic regions of Guanine nucleotidebinding protein $\mathrm{G}$ subunit $(G N A S)\left(\mathrm{A} 3: 4,665,802 ; \mathrm{P}_{\text {genome }}=4.44 \times 10^{-05}\right)$, Growth regulating oestrogen receptor binding 1 (GREB1) (A3:134,518,080; $\left.\mathrm{P}_{\text {genome }}=6.13 \times 10^{-05}\right)$, Zinc finger matrin-type 4 (ZMAT4) (B1:44,235,566; $\left.\mathrm{P}_{\text {genome }}=6.85 \times 10^{-05}\right)$ and EF-hand calcium binding domain $5\left(\right.$ EFCAB5) $\left(\mathrm{E} 1: 16,917,823 ; \mathrm{P}_{\text {genome }}=4.02 \times 10^{-05}\right)$ genes.

Five regions of association on chromosomes A3, B1 and E1 were defined based on LD clumping with $\mathrm{r}^{2}>0.8$ to the top regional SNV and used to identify FDM-associated haplotypes within each of these clumps (Table 1). The highest associated haplotype spanned the interval chrA3:134,425,431-134,601,739 bp. This region spanned genes; Lipin-1 (LPIN1), Neurotensin receptor 2 (NTSR2) and GREB1 and harboured a SNV within GREB1 $\left(P=4.33 \times 10^{-06}\right)$ unique to cases.

The second highest associated haplotype spanned the interval chrB1:48,056,021-48,848,288 bp $\left(P=4.69 \times 10^{-06}\right)$ and was present in $27.3 \%$ of cases and $3.3 \%$ of controls. Across this region, seven synonymous 

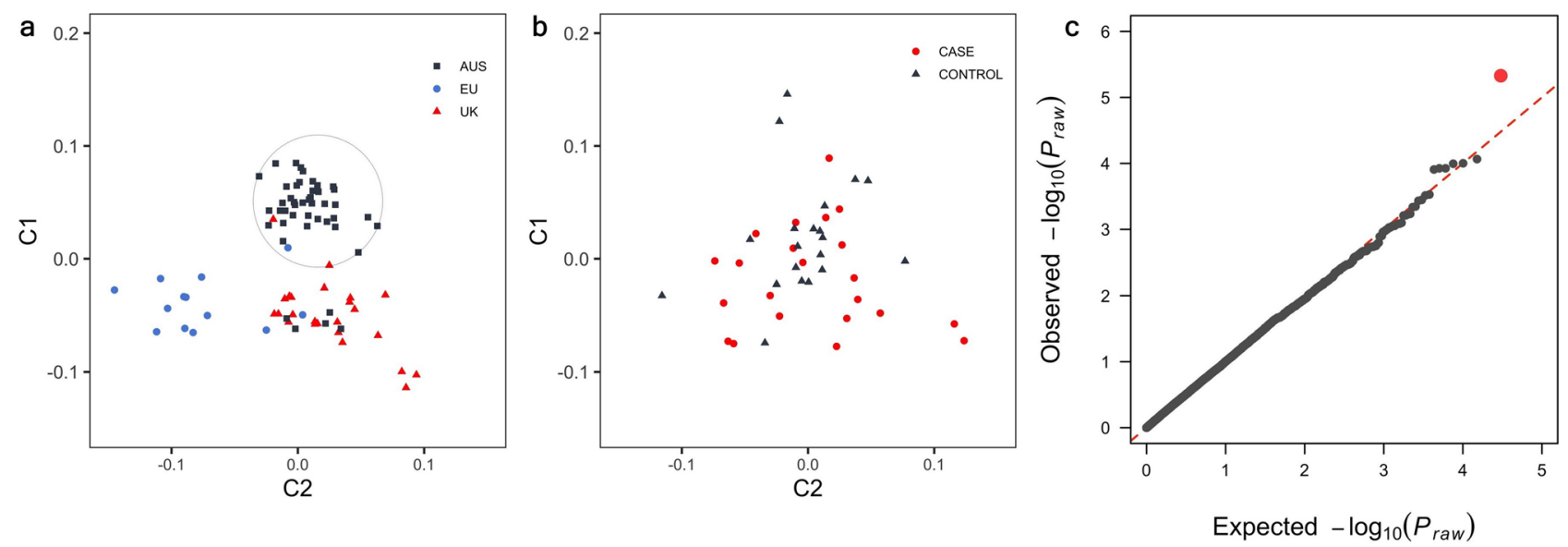

Figure 1. Multi-dimensional scaling and quantile-quantile plot of diabetic and non-diabetic Burmese cats. (a) Multi-dimensional scaling distribution of Burmese cats of Australian, British and European (HK) provenance in two dimensions. Samples included within the Australian cluster (circled) were included in the initial casecontrol association analysis. (b) Multi-dimensional scaling distribution of diabetic and non-diabetic Burmese cats in the Australian cluster shown in two dimensions (c) Quantile-quantile plot showing limited inflation of the test statistics with a genomic inflation factor $(\lambda=1.03)$.
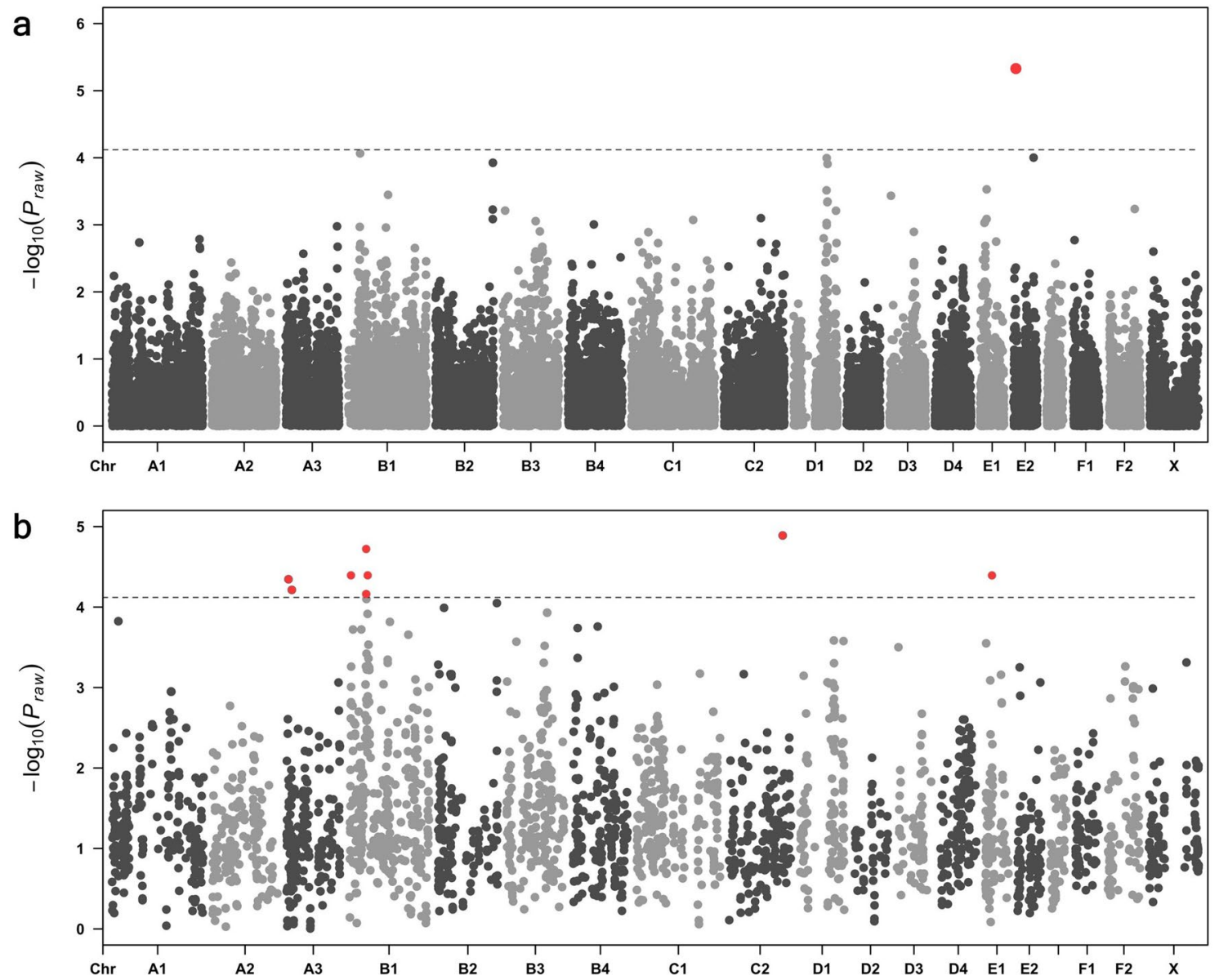

Figure 2. Case-control genome wide association analysis performed in two stages in the Burmese breed. (a) Manhattan plot summarising initial analysis of 20 cases and 22 controls in the Australian cluster shows a marker on chromosome E1 b. The top $10 \%$ of markers (3022 SNVs) run in the initial association analysis were run in an expanded association analysis of 82 Burmese cats of Australian, European and British provenance, comprising 22 cases and 60 controls. Signals that maintained or increased their significance above the empirical genomewise significance threshold $\left(P<7.6 \times 10^{-5}\right)$ are highlighted in red. Loci passing this threshold were observed on chromosomes A3, B1 and E1. 


\begin{tabular}{|c|c|c|c|c|c|c|c|c|c|}
\hline Chr & Position & $P$ & Allele & Haplotype block & Size (kb) & Associated haplotype & Case:control freq & Haplotype P & Genes \\
\hline \multirow[t]{2}{*}{ A3 } & $4,665,802$ & $4.44 \mathrm{E}-05$ & C & $4,396,199-4,741,413$ & 345 & GGCG & 0.232:0.042 & 0.0372 & $\begin{array}{l}\text { ATP5F1E TUBB1 } \\
\text { PRELID3B NELFCD GNAS }\end{array}$ \\
\hline & $134,518,080$ & $6.13 \mathrm{E}-05$ & A & $134,425,431-134,601,739$ & 176 & GAAG & 0.168:0 & $7.00 \mathrm{E}-04$ & LPIN1 NTSR2 GREB1 \\
\hline \multirow{2}{*}{ B1 } & $44,398,531$ & $1.88 \mathrm{E}-05$ & C & $43,116,211-44,435,725$ & 1319 & $\begin{array}{l}\text { AGGAGAGAGAGCGAA } \\
\text { GGGCA }\end{array}$ & 0.182:0.017 & $2.50 \mathrm{E}-04$ & $\begin{array}{l}\text { ANK1 GINS4 GPAT4 } \\
\text { SFRP1 ZMAT4 }\end{array}$ \\
\hline & $48,213,950$ & $3.98 \mathrm{E}-05$ & A & $48,056,021-48,848,288$ & 792 & $\begin{array}{l}\text { AAAGGGCAAGAA } \\
\text { CGAGA }\end{array}$ & $0.273: 0.033$ & $4.69 \mathrm{E}-06$ & UNC5D \\
\hline E1 & $16,917,823$ & $4.02 \mathrm{E}-05$ & A & $16,577,377-17,262,839$ & 685 & GGGGGCAAGAGGAA & $0.636: 0.898$ & 0.0052 & $\begin{array}{l}\text { TMIGD1 BLMH SLC6A4 } \\
\text { NSRP1 EFCAB5 SSH2 }\end{array}$ \\
\hline
\end{tabular}

Table 1. LD clumping and haplotype analysis of association signals from analysis 2 identified risk haplotypes on chromosomes A3, B1 and E1 across 82 Burmese cats.

\begin{tabular}{|c|c|c|c|c|c|c|}
\hline Chromosome & Position (gDNA) & Sequence change (cDNA) & Variant id & Gene & Consequence & Location \\
\hline \multirow{5}{*}{ A3 } & g.4531693 & c. $1803 \mathrm{G}>\mathrm{A}$ & - & CTSZ & Synonymous & Exon 5 \\
\hline & g.4538198 & c. $811 \mathrm{C}>\mathrm{T}$ & - & NELFCD & Synonymous & Exon 7 \\
\hline & g.4538472 & c. $751 \mathrm{C}>\mathrm{T}$ & rs783705891 & NELFCD & Synonymous & Exon 6 \\
\hline & g.4678284 & c. $528 \mathrm{~A}>\mathrm{G}$ & - & NESP55 & Synonymous & Exon 1 \\
\hline & g.4678485 & c. $729 \mathrm{G}>\mathrm{A}$ & - & NESP55 & Synonymous & Exon 1 \\
\hline \multirow{9}{*}{ B1 } & g.35028512 & c. $474 \mathrm{G}>\mathrm{A}$ & - & LOXL2 & Missense & Exon 2 \\
\hline & g. 35028658 & c. $620 \mathrm{C}>\mathrm{T}$ & - & LOXL2 & Synonymous & Exon 2 \\
\hline & g.35028712 & c. $674 \mathrm{G}>\mathrm{A}$ & - & LOXL2 & Synonymous & Exon 2 \\
\hline & g.35028781 & c. $743 \mathrm{C}>\mathrm{T}$ & - & LOXL2 & Synonymous & Exon 2 \\
\hline & g.35274559 & c. $136 \mathrm{G}>\mathrm{A}$ & - & PEBP4 & Missense & Exon 1 \\
\hline & g.43228852 & c.768C $>\mathrm{T}$ & - & ANK1 & Synonymous & Exon 5 \\
\hline & g. $43227755 \mathrm{C}>\mathrm{T}$ & - & - & ANK1 & Splice region & Intron 4 \\
\hline & g. $43235911 \mathrm{C}>\mathrm{T}$ & - & - & ANK1 & Splice region & Intron 9 \\
\hline & g.48700205 & c. $1176 \mathrm{G}>\mathrm{A}$ & rs783910583 & UNC5D & Synonymous & Exon 10 \\
\hline
\end{tabular}

Table 2. Coding variants matching FDM-risk haplotypes across GWAS loci on chromosomes A3 and B1 and variants segregating in cases across both $\mathrm{ROH}$ on $\mathrm{B} 1$.

and splice region variants in Cathepsin Z (CTSZ), Negative elongation factor CD (NELFCD), Neuroendocrine secretory protein 55 (NESP55), Ankyrin 1 (ANK1) and UNC-5 netrin receptor (UNC5D) (Table 2), 708 intronic, two splice region variants, two 5' UTR variants in GPAT4 and GINS4 and seven 3' UTR variants in CTSZ and NELFCD matched risk haplotypes across the five FDM-associated haplotype blocks (Table S3). Most notably, variants matching the FDM-risk haplotype on $\mathrm{B} 1$ were identified in common T2D candidate gene, ANK1. Of WGS samples, two cases were heterozygous for both ANK1 splice variants, all other individuals were homozygous for the reference allele. SNV, g. $43227755 \mathrm{C}>\mathrm{T}$, was located within $5 \mathrm{bp}$ of the region of a constitutive donor splice site at the start of intron 4 and g.43235911C $>$ T was located 2 bp upstream of a constitutive acceptor splice site at the end of intron 9.

Runs of homozygosity. The total number of SNVs included in $\mathrm{ROH}$ analysis was 52,933. A total of 5079 $\mathrm{ROH}$ were identified across all individuals. The distribution of sizes of $\mathrm{ROH}$ was consistent across populations. Most of the observed $\mathrm{ROH}$ were less than $20 \mathrm{Mb}$ in size, with $46.9 \%, 48.1 \%$ and $46.5 \%$ being observed between 5 and $10 \mathrm{Mb}$ in size (Fig. 3a). Limited by the distribution and density of SNVs on the feline genotyping array, no $\mathrm{ROH}<1 \mathrm{Mb}$ were detected. Australian samples displayed larger spans of $\mathrm{ROH}$, with two samples displaying a total length of ROH greater than $750 \mathrm{Mb}$. These two samples displayed the highest inbreeding coefficients. No correlation was observed between case-control status and the total length of $\mathrm{ROH}$, number of ROH or extent of inbreeding in Burmese cats. Inbreeding coefficient measures $\mathrm{FROH}_{\text {cov }}$ and $\mathrm{FROH}_{\text {aut }}$ across all samples were highly correlated (Fig. 3b; $\mathrm{r}=1.0 ; P<2.26 \times 10^{-16}$ ). While $\mathrm{FROH}_{\text {aut }}$ is the more commonly reported inbreeding coefficient statistic, $\mathrm{FROH}_{\text {cov }}$ allows maximal possible genome coverage. Hence, we have reported both here. $\mathrm{FROH}_{\text {aut }}$ and $\mathrm{FROH}_{\text {cov }}$ reported an inbreeding coefficient $\sim 0.24$ across all samples. Inbreeding $\left(\mathrm{FROH}_{\text {cov }}\right)$ was consistent among Australian $\left(\mathrm{FROH}_{\mathrm{cov}}=0.25\right)$, UK $\left(\mathrm{FROH}_{\mathrm{cov}}=0.23\right)$ and $\mathrm{EU}\left(\mathrm{FROH}_{\mathrm{cov}}=0.22\right)$ populations (Fig. 3b).

Genomic regions containing the most common $\mathrm{ROH}$ across all samples were identified across all autosomes (Fig. 3c). ROH on chromosomes B1, B3, D1 and D4 revealed regions potentially under selection in the breed, with both $\mathrm{ROH}$ on chromosome B1 containing FDM-risk variants (Table 2). ROH spanning chrB3:20,948,939-28,536,357 contained 22 genes, none of which are associated with known feline phenotypes. This $\mathrm{ROH}$ was observed in $>75 \%$ of samples and was syntenic with a region of human chromosome 15 , previously 

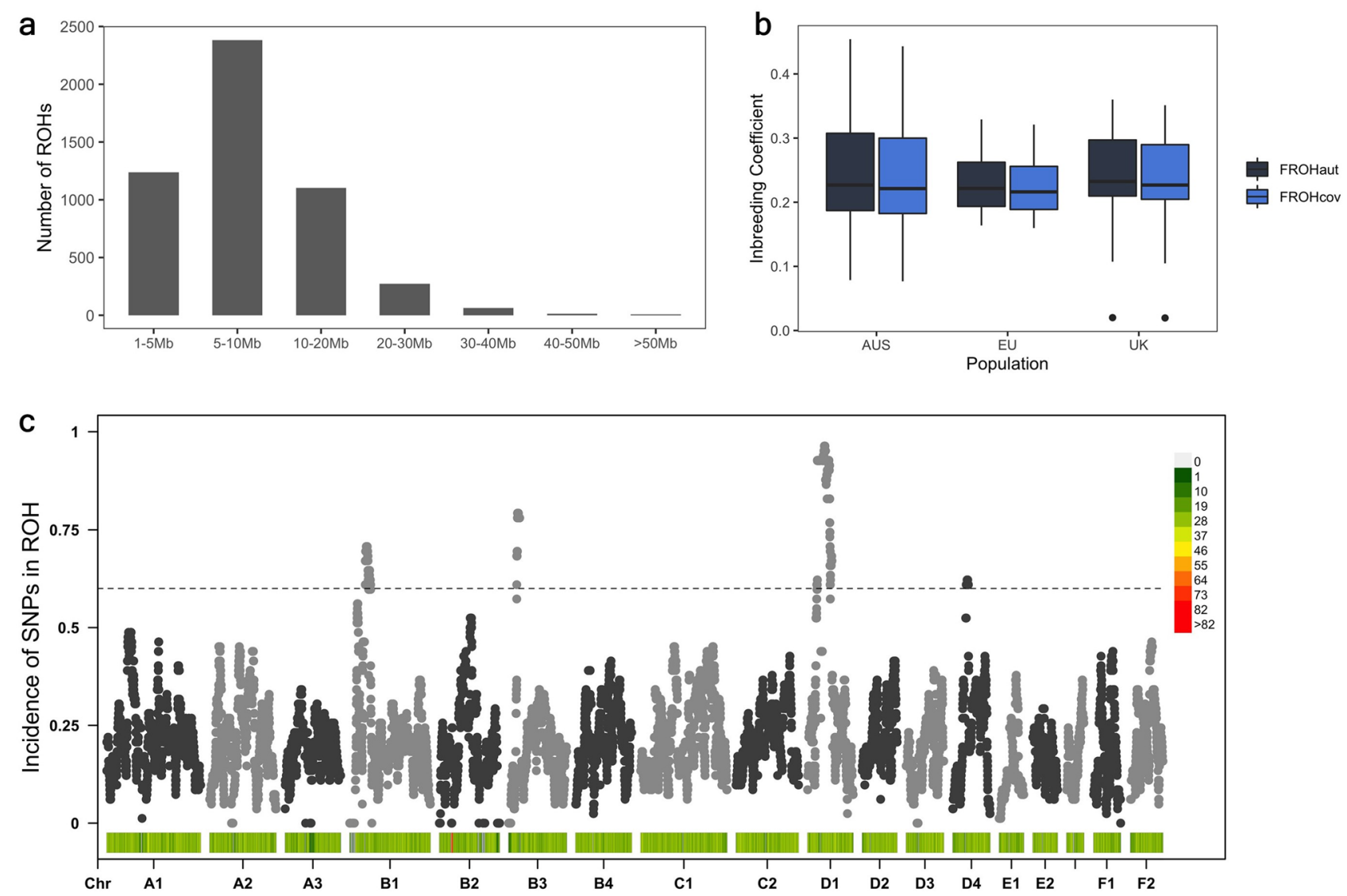

Figure 3. ROH analyses on 82 Burmese samples of Australian, British and European provenance. (a) Most $\mathrm{ROH}$ were found in the size ranges 1-20 Mb across all individuals. (b) Inbreeding coefficient measurements were equivalent across all populations. c. Autosomal distribution of the incidence of SNVs in ROH measured across all samples.

implicated in Prader Willi syndrome (PWS) (OMIM 176270) and oculocutaneous albinism (OMIM 203200). FDM-risk variants were found to segregate in Non-Imprinted gene in Prader-Willi syndrome/Angelman syndrome (NIPA1; OMIM:608145) and Gamma-aminobutyric Acid Receptor, Gamma-3 (GABRG3; OMIM:600233).

An ROH spanning chrD1:37,995,037-57,240,116 upstream of the FDM-associated locus was observed in $>90 \%$ of all Burmese cats. This locus contained the Tyrosinase (TYR) gene that has been previously Intronic risk variants in glutamate receptor, metabotropic 5 (GRM5), Dexamethosone-induced gene-2 (DIG2) and Myosin VIIA (MYO7A) gene were found across WGS samples. The FDM locus with indicative association on chromosome D1 was $40 \mathrm{Mb}$ upstream of the $\mathrm{ROH}$ spanning chrD1:37,995,037-57,240,116. The ROH on chrD4:34,892,052-40,360,453, observed in $62 \%$ of Burmese samples, spanned the Tyrosinase-related protein 1 (TYRP1) gene, implicated in brown coat colour in cats (OMIA 001249-9685). Intronic risk variants in protein tyrosine phosphate receptor delta $(P T P R D)$ were detected in WGS samples.

Two ROH flanking the centromere on chromosome B1 were detected across all populations. Both were syntenic to a region on human chromosome 8 and overlapped the putative ticked coat phenotype locus in cats (OMIA 001484-9685). The first spanned chrB1:34,395,302-38,202,712 at a lower incidence (0.49) than the second, chrB1:40,408,022-54,187,390 bp (0.69). Missense and synonymous risk variants in Lysyl Oxidase homolog 2 (LOXL2) and Phosphatidylethanolamine-Binding Protein 4 (PEBP4) genes segregated in FDM-cases (Table 2). SNVs within the chrB1:34,395,302-38,202,712 bp ROH were in moderate $\mathrm{LD}\left(\mathrm{r}^{2}=0.5\right)$ to the highest associated SNV in the chrB1:40,408,022-54,187,390 bp ROH (Fig. 4a). ChrB1:40,408,022-54,187,390 overlapped the most significant region of FDM-association identified in analysis 2 (Fig. $4 \mathrm{~b}$ ) and was observed in $80 \%$ of controls and $49 \%$ in cases and contained 65 genes. FDM-risk variants segregating in cases could not be detected as only one diabetic WGS sample had the chrB1:40408022-54187390 ROH. A homozygous missense variant (c.163A > G) in exon 1 of Epoxide hydrolase 2 (EPHX2) was fixed across all WGS samples. Annotated FDM-risk variants discovered across $\mathrm{ROH}$ are presented in table S4.

\section{Discussion}

We sought to identify novel genetic loci associated with FDM in the Australian Burmese population. GWAS exploits the non-random coinheritance of genetic variants (LD) to assay thousands of markers for an association with any phenotypic trait. The Burmese breed is characterised by a low fraction of GWAS-informative SNVs on the $63 \mathrm{~K}$ array, and only $49 \%$ of the available array markers were included in our analysis. However, the low allele frequency spectrum used in array-based association analyses, coupled with the genetic profile of this breed limits 

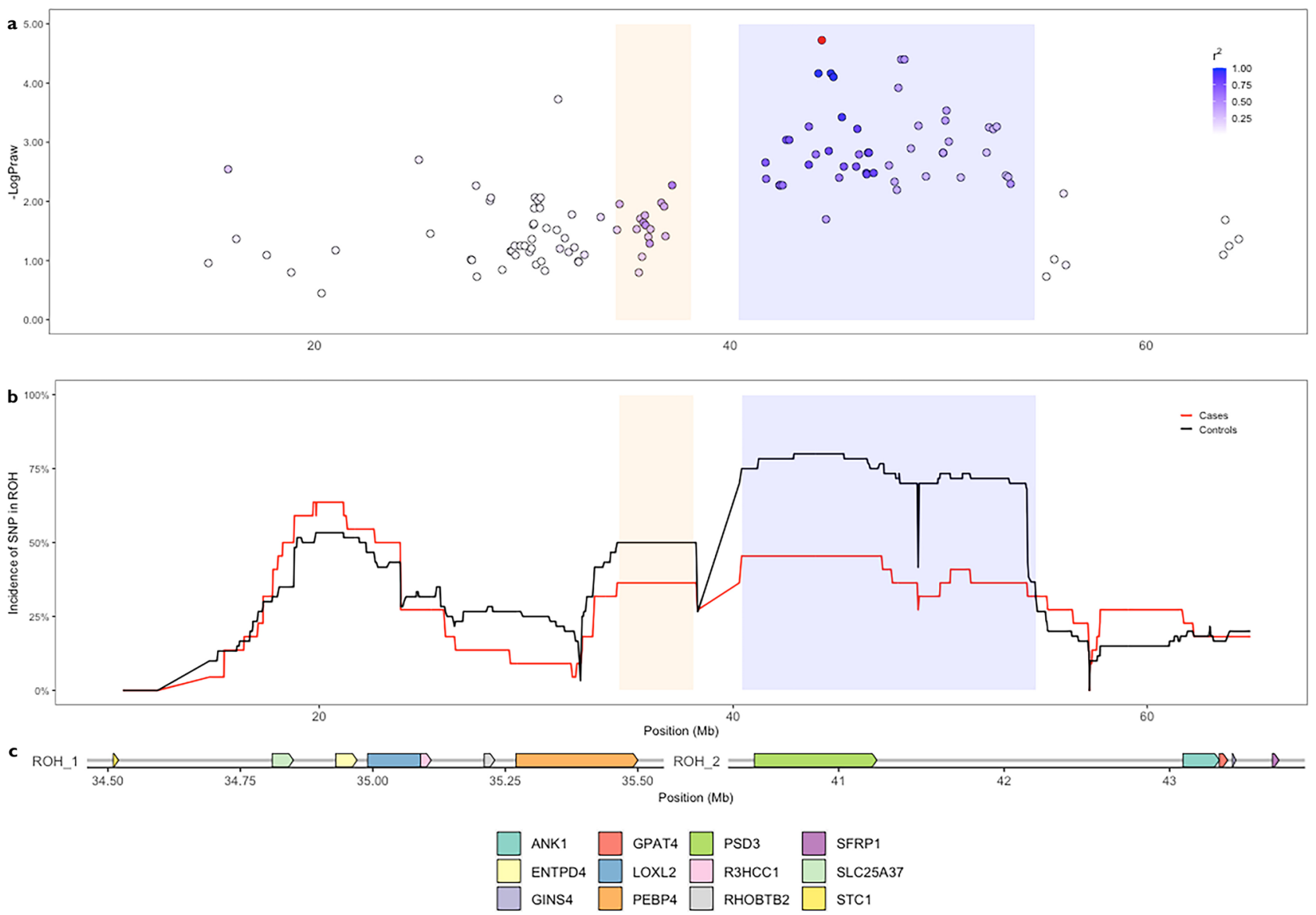

Figure 4. Overlapping FDM associated loci on chromosome B1 was identified in both ROH and GWAS analyses. (a) The distribution of SNVs flanking the highest associated SNV (red). Haplotype testing narrowed this to a region spanning 42-49 $\mathrm{Mb}$. (b) Two $\mathrm{ROH}$ were observed on chromosome B1. ROH_1 (orange) was $4 \mathrm{Mb}$ downstream of the GWAS identified FDM-association loci. ROH_2 (blue) was found to overlap the FDMassociated haplotype block. The incidence of SNVs included in ROHs were observed differentially between cases and controls with two adjacent peaks of higher frequently in controls than cases. c. Targeted variant discovery in these $\mathrm{ROH}$ and GWAS-identified regions revealed coding variants in genes.

the need to control for false-positives. Given the extent of LD observed in pedigreed cat breeds, traditionally conservative forms of correction (i.e. Bonferroni correction) are considered excessive. Empirical estimations of genome-wide significance (i.e. 95\% CIs from the distribution of raw P values) are more conservative than what is typically used in human GWAS but are adequate in population isolates ${ }^{16,36}$.

Genomic clustering of samples was concordant with geographical provenance. Geographic population stratification was expected as the cats in this study were collected from British, European and Australian populations that have each been subjected to population bottlenecks during their local breed development. Population substructure in GWAS cohorts is identified as a cause of potentially spurious associations ${ }^{37}$. Imprecise modelling of genetic relatedness within GWAS sample populations can cause substantial inflation of test statistics and potentially false association signals. Further, limiting study samples to entirely unrelated individuals is difficult in pedigreed breeds, such as the Burmese. To limit the effects of hidden relatedness and population stratification, the linear mixed-model (LMM) approach implemented by EMMAX was used. LMM have been shown to perform well in comparison to traditional family-based association tests ${ }^{38}$.

The Burmese cats in this study displayed high homozygosity and long ROH consistent with previous reports ${ }^{14}$. The distribution of $\mathrm{ROH}$ across the Burmese samples was consistent with previous results ${ }^{39}$. Long $\mathrm{ROH}(>5 \mathrm{Mb})$ are indicative of recent inbreeding, unbroken by historical recombination events. No detectable difference in inbreeding coefficients between FDM cases and control groups was identified. Several factors influence the resolution of $\mathrm{ROH}$ calling, including marker density, marker distribution and genotype call quality. Therefore, for most populations, medium density genotyping arrays do not lend themselves to high resolution analysis of $\mathrm{ROH}^{40}$. For this analysis, minor allele frequency (MAF) and LD pruning were not employed in the ROH detection as both have been shown to mask the detection of true ROH by limiting genome coverage ${ }^{39}$. Long ROH (1-10 Mb) made up the largest size category observed across all populations, accounting for over $70 \%$ of $\mathrm{ROH}$ observations. Large $\mathrm{ROH}$ may persist in a population because of low rates of local recombination particularly in genomic regions that are subject to positive selection pressures. The risk of T2D is increased by moderate inbreeding and consanguinity within isolated populations ${ }^{41-43}$. ROH did not implicate autozygosity as a risk 
factor for FDM in Burmese cats, as diabetic cats did not display a higher number of ROH or higher inbreeding coefficient than non-diabetic cats.

Selective sweeps, indicative of positive selection, manifest by the reduction of genetic variation surrounding a beneficial mutation, and occur due to positive selection pressure increasing the frequency of the favourable allele over time ${ }^{44}$. In cats, at least eight loci are involved in coat colour determination, with various combinations of these responsible for extensive phenotypic variation. Genes, TYR and TYRP1, inside ROH support strong selection of tyrosine metabolism and common Burmese coat 'ticking' and colour phenotypes ${ }^{45-47}$. Tyrosine metabolism influences the development, differentiation and proliferation of melanocytes, the construction and transport of the melanosome and the synthesis of melanin ${ }^{48}$. Short selective sweeps, indicative of extensive LD, have been associated with T2D in isolated human populations ${ }^{49}$. Sweeps can cause a shift in the allelic frequency of a selected allele and the 'hitchhiking' alleles in their vicinity. Pancreatic islets of FDM and T2D patients are characterised by reduced beta cell function and decreased insulin gene expression ${ }^{50,51}$. FDM-risk variants within these selective sweeps identified GRM5 and DLG2 as candidates for beta cell dysregulation, as both are involved in glucose-stimulated insulin secretion and hyperglycaemia susceptibility in rodent and human ${ }^{52-54}$. Additionally, PTPRD contained within the chromosome $\mathrm{D} 4 \mathrm{ROH}$ has been associated with progression to diabetes in humans through enhanced insulin resistance ${ }^{55,56}$. The $\mathrm{ROH}$ on chromosome B3 overlapped a syntenic loci in humans implicated in Prader Willi Syndrome (PWS). T2D has been found to affect between 7 and 24\% of PWS patients, far exceeding the prevalence in the general population ${ }^{57,58}$. This is likely a consequence of insulin resistance resulting from morbid obesity however PWS patients also exhibit a state of hypoinsulinaemia without expected insulin resistance despite their obese state. Deficits in pancreatic islet development may play a role in the PWS phenotype ${ }^{59,60}$. NIPA1 is a magnesium transporter, upregulated in response to reduced magnesium concentration $^{61}$. Variants in NIPA1 have previously been associated with T2D risk ${ }^{62}$ and GABRG3 is an early childhood obesity gene contributing to PWS phenotype ${ }^{63}$. The basis of the diabetic state in obese PWS patients is currently unclear but the PWS locus contains epigenetically imprinted genes that serve as viable candidates for FDM.

The most compelling FDM-association was provided by the locus on chromosome B1, identified in both $\mathrm{ROH}$ and GWAS analyses. Coding variants matching the risk-haplotype segregated in ANK1, an established T2D candidate gene associated with decreased beta-cell function in humans ${ }^{64,65}$. Feline $A N K 1$ is highly orthologous (93.89\%) to human $A N K 1$ sequence and multiple $A N K 1$ isoforms with affinities for various target proteins are expressed in a tissue specific manner ${ }^{66-68}$. Transcripts of varying size are present in tissues essential to glucose metabolism: skeletal muscle ${ }^{69}$, pancreas, adipose and liver ${ }^{70}$. Splice region variants identified in this study may be influential in the molecular function of feline ANK1 isoforms, but any potential impact of these will be dependent on tissue-specific expression of $A N K 1$ isoforms. Alternatively-spliced $A N K 1$ transcripts are functionally diverse and variants in regulatory regions have been implicated in altered molecular function of the various human isoforms and their role in T2D ${ }^{71}$. The physiological role of $A N K 1$ in T2D pathogenesis is unconfirmed but Ankyrin B (ANK2) regulates ATP sensitivity in murine pancreatic beta cells ${ }^{72}$. Additionally, SNVs in the ANK1 promoter region have been found to increase intramuscular fat content in pigs $^{73}$ and increased muscle-specific $A N K 1$ expression in human skeletal muscle ${ }^{71}$ implying SNVs in the ANK1 promoter region may play a role in the development of insulin resistance.

$\mathrm{ROH}$ analysis implicated two loci on chromosome B1 as FDM-risk loci, containing risk variants segregating in cases and across the breed, further highlighting the genetic complexity of FDM. Both partially overlapped the semi-dominant Abyssinian 'ticked' coat locus responsible for the homogenous agouti coat with no body markings characteristic of Burmese cats ${ }^{47}$. Across chrB1:34,395,302-38,202,712, variants segregated in cases in LOXL2, previously implicated in nephropathy and retinopathy in T2D patients ${ }^{74,75}$, indicating these may play a critical role in the progression to FDM. Diabetic nephropathy is not routinely recognised in diabetic cats, although diabetic retinopathy has been reported ${ }^{76}$. Dyslipidaemia is a critical factor in the early inflammatory response in the development of retinopathy ${ }^{77}$. LOXL2 overexpression is considered a potential target for treatment of vascular changes involved in diabetic retinopathy ${ }^{78}$.

Inherited derangements in lipid metabolism have been described in the Burmese breed ${ }^{20,79}$ and may be related to the high prevalence of FDM. Familial hypercholesterolaemia (FH) is a common autosomal dominant disorder of lipoprotein metabolism, with variable phenotypic presentation in humans ${ }^{80}$. Variants in EPHX2 have been found to exacerbate the dysfunction of the Low-density lipoprotein receptor (LDLR) gene in $\mathrm{FH}^{81}$ and are associated with insulin resistance in T2D patients ${ }^{82}$. Defects in $L D L R$ result in disturbed clearance of low-density lipoprotein cholesterol (LDL-C) and the clinical presentation varies widely depending on the segregation of risk alleles and haplotype. A missense substitution (c.163A > G) in EPHX2 was fixed across all WGS Burmese samples within the chrB1:40,408,022-54,187,390 bp ROH. Phenotypic heterogeneity is present between homozygous and heterozygous FH patients, with a range of increased plasma triglyceride levels, likely influenced by modifying gene-gene interactions. A syndrome similar to FH has been described in Burmese cats with affected individuals exhibiting significantly elevated plasma triglyceride concentrations, lipid aqueous and delayed triglyceride clearance compared with other breeds ${ }^{83-85}$. Post-prandial hypertriglyceridemia has been described in cats with inherited Lipoprotein lipase (LPL) factors ${ }^{86}$ with variable phenotypic presentation in homozygous and heterozygous individuals. Further studies will be required to determine whether the lipid metabolism defects in Burmese cats can be attributed to EPHX2 dysfunction and any potential contribution to increased risk of FDM.

This study has unveiled genomic regions underlying dysfunctional metabolic processes predisposing Burmese cats to FDM, highlighting lipid metabolism as a contributing factor. Larger cohorts of comprehensively phenotyped individuals across multiple breeds are needed to validate the genetic risk factors presented here. The segregation of polymorphisms across autozygous regions and identification of risk-haplotypes reveal a potential highly penetrant recessive locus on chromosome B1. This strategy for identifying risk-loci across a predisposed population suggests the interaction of multiple genes across a fixed number of loci are likely responsible for FDM 
in Australian Burmese cats. The regions reported here characterise a window of FDM association containing candidate genes for further investigation in larger studies with prospective clinical phenotyping. Detailed characterisation of the genetic risk factors involved in the pathogenesis of FDM, including the allelic variants and candidate genes presented here, will provide a more comprehensive understanding of the molecular mechanisms involved and the genetic interaction profiles responsible for this disease, and for T2D in humans. Building on insights gained from this study, future work can potentially pinpoint population specific allele frequency profiles.

\section{Materials and methods}

Clinical diagnosis and sample collection. Eighty-two Burmese cats, comprising 22 diabetic and 60 non-diabetic individuals were submitted for genotyping analysis on the Illumina Infinium iSelect $63 \mathrm{k}$ Cat DNA genotyping array. Genomic DNA was extracted from whole blood using the DNeasy blood and tissue kit (Qiagen GmbH, Germany) or Performagene PG-100 buccal swabs (DNA Genotek, Canada). All cases (15 male, 7 female) had been diagnosed with FDM based on persistent fasting hyperglycaemia, glycosuria with clinical signs; weight loss, polydipsia and polyphagia by a qualified veterinarian at the University of Sydney Veterinary Teaching Hospital and Animal Diabetes Australia. Unaffected Burmese were collected from an database of adult Burmese cats. This included 23 Australian and 24 British Burmese and 13 European Burmese, nine European cats were members of the same pedigree ${ }^{19}$. Samples from non-diabetic Burmese (26 male, 34 female) were all collected by a qualified veterinarian and showed no clinical signs of FDM at the time of their presentation for clinical examination and sample collection and had never previously been diagnosed with FDM. Veterinary records of controls were checked for indicators of disease related to diabetes before they were included.

Remapping array variants to feline 9.0 genome assembly. To determine the exact position of feline array single nucleotide variants (SNV) on the Felis_catus_9.0 genome assembly, we performed a Basic Local Alignment Search ${ }^{87}$ using SNV probes available in the feline manifest ${ }^{88}$. A FASTA file was created using the SNV identifier and flanking genomic sequence upstream and downstream of each SNV in top orientation. The longest flanking sequence was retained and output in FASTA format. A custom BLAST database was prepared using BLAST $+{ }^{87}$ to make the reference FASTA sequence searchable. A nucleotide BLAST search was performed and output was filtered to collect the single best hit for each sequence, hits that failed to return any result, hits that failed to reach the base position immediately adjacent to the SNV and those that had an E-value greater than $1 \mathrm{e}-05$ were rejected.

Population structure and quality control. Quality control was carried out for 82 samples and 61,386 SNVs using PLINK 1.9 $9^{89}$. First, we identified possible duplicate samples and outliers based on pairwise genetic distances (-genome) and removed one sample from each pair with an identity by descent (IBD) estimate $>0.65$. Population stratification was evaluated using a MDS plot with two dimensions (-mds). Marker-based QC included pruning the total set of SNVs at a MAF (-maf) of 0.05 and a SNV (-mind) and individual call rate (-geno) of $>90 \%$.

Case-control genome-wide association study and haplotype analysis. Testing for association between FDM and markers on the feline genotyping array was performed in two stages using Efficient MixedModel Association eXpedited (EMMAX ${ }^{90}$. Given all cases were of Australian provenance, an initial association analysis (analysis 1) was performed on samples within the unstratified Australian cluster. To validate the associations observed in the Australian cluster, a second association analysis (analysis 2) run in EMMAX included an expanded group of individuals from Australian, UK and EU populations ( 22 cases, 60 controls) and the top 10\% of association signals from analysis 1 . The genome-wide significance threshold in both analyses was calculated based on empirical 95\% confidence intervals (CIs). The probability distribution was determined by running the GWAS 1000 times with randomly permuted phenotypes. The genome-wide significance threshold was set at the 97.5\% upper CI (based on a two-tailed distribution) $\left(P<7.6 \times 10^{-5}\right)$ (Karlsson et al. $\left.{ }^{16}\right)$.

Regions of association were refined using LD clumping (-clump) in PLINK. First, a region of weak LD $\left(r^{2}>0.2\right)$ was defined within $5 \mathrm{Mb}$ of each top SNV and then the region was narrowed to a single locus of high LD $\left(r^{2}>0.8\right)$ within $2 \mathrm{Mb}$ of the highest associated SNV per locus. The refined regions were submitted for haplotype analysis with HAPLOVIEW ${ }^{91}$. FDM-associated haplotype blocks were examined in all 82 individuals and were defined using the four-gamete rule ${ }^{92}$. Consecutive haplotype blocks with a multiallelic $\mathrm{r}^{2}$ value of 1 were combined and blocks containing the top associated SNVs were used to define our FDM-associated loci. Significance of FDM-associated haplotype blocks was measured by running 10,000 permutations.

Runs of homozygosity analysis. $\mathrm{ROH}$ analysis was performed to identify FDM-associated regions of autozygosity using PLINK (-homozyg function). The input settings for minimal density of SNVs, maximal gap size, scanning window length and threshold settings were determined empirically ${ }^{39}$. The ROH analysis was run using a maximal gap size of $300 \mathrm{~kb}$ (-homozyg-gap) and scanning window size setting of minimal density (homozyg-density) at $80 \mathrm{~kb} / \mathrm{SNV}$ at a genome coverage of $98.9 \%$. Additional settings were; a scanning window hit rate of 0.05 (-homozyg-window-threshold), maximum of one heterozygous SNV per final ROH segment (-homozyg-het) and a minimum of 94 SNVs in each final ROH (-homozyg-SNV) (Table S2). Inbreeding coefficients $\left(\mathrm{F}_{\mathrm{ROH}}\right)$ for genotyped individuals were calculated based on the length of the autosomal genome and the length of the genome covered by feline array markers (Meyermans et al. 2019). Correlations between inbreeding coefficients $\mathrm{F}_{\mathrm{ROHcov}}$ and $\mathrm{F}_{\mathrm{ROHaut}}$ were measured using a Pearson's correlation test. We did not prune SNVs based on MAF or LD. ROH on chromosomes B1, B3, D1 and D4 were examined for syntenic regions using the Ensembl Bioinformatics database and a database search was performed using the BLAST algorithm. Compara- 
tive genome analyses of $\mathrm{ROH}$ on chromosomes $\mathrm{B} 1$ and $\mathrm{B} 3$ were undertaken. $\mathrm{ROH}$ distributions were compared between the Australian cluster and the expanded group of Burmese and between cases and controls across all autosomes to identify any regions associated with FDM.

Risk variant discovery and annotation. Genomic DNA was extracted from whole blood samples of five Australian Burmese cats ( 3 cases, 2 controls) included in GWAS analysis, using a phenol-chloroform extraction protocol. DNA samples were submitted for whole genome sequencing (WGS). Illumina paired-end libraries were prepared and sequenced on the Illumina HiSeq 2000 platform with 150 bp paired-end reads $(\sim 12-21 \times$ coverage). An additional three WGS samples, of unknown diabetic phenotype, available on Sequence Read Archive (SRA) were downloaded (SRX2376210, SRX2669131, SRX2376201) ( 12-27× coverage). All samples were aligned to the Felis_catus_9.0 reference assembly using BWA-mem ${ }^{93}$. Base quality score recalibration, indel realignment and duplicate removal was performed using Genome Analysis ToolKit (GATK) ${ }^{94}$. Genome-wide variant detection was performed using GATK's HaplotypeCaller according to best practices and variants filtered for sequence depth $(\mathrm{DP}>10)$, quality of alignment $(\mathrm{GQ}>20)$ and strand bias ${ }^{95}$. Given the complex phenotypic presentation of FDM and the unknown clinical phenotype of the SRA samples, associated haplotype blocks were filtered according to presence or absence of risk haplotypes across the eight WGS samples, rather than clinical information of each individual. ROH were examined for FDM risk variants segregating in affected WGS samples and potential risk factors across the breed. Filtered variants were analysed with Ensembl's Variant Effect Predictor (VEP) tool ${ }^{96}$. Sequence variants were further filtered for genic variants and annotated variants with Sort Intolerant From Tolerant (SIFT) tool ${ }^{97}$.

Ethical approval. Recommendations from the Australian Code for the Care and Use of Animals for Scientific Purposes was strictly adhered to throughout this study. Research was conducted at The University of Sydney, under Animal Ethics Committee approval no: N00/9-2009/3/5109, 24 September 2009. Blood and buccal swab samples were all collected a veterinarian or donated by owners and breeders.

\section{Data availability}

Genotyping array data is available at $10.6084 / \mathrm{m}$ 9.figshare.12561815 and 10.6084/m9.figshare.12561770. Whole genome sequence data for five phenotyped Australian Burmese samples can be accessed freely upon request to the 99Lives Consortium Coordinator, L. A. Lyons (lyonsla@missouri.edu). Whole genome sequence data for three Burmese samples of unknown clinical status can be accessed via NCBI Sequence Read Archive under accession codes: SRX2376208, SRX2376209 and SRX2376210.

Received: 29 June 2020; Accepted: 22 October 2020

Published online: 05 November 2020

\section{References}

1. Henson, M. S. \& O'Brien, T. D. Feline models of type 2 diabetes mellitus. ILAR J. 47, 234-242. https://doi.org/10.1093/ilar.47.3.234 (2006).

2. Osto, M., Zini, E., Reusch, C. E. \& Lutz, T. A. Diabetes from humans to cats. Gen. Comp. Endocrinol. 182, 48-53. https://doi. org/10.1016/j.ygcen.2012.11.019 (2013).

3. Hoenig, M. Comparative aspects of human, canine, and feline obesity and factors predicting progression to diabetes. Vet. Sci. https ://doi.org/10.3390/vetsci1020121 (2014).

4. Samaha, G., Beatty, J., Wade, C. M. \& Haase, B. The Burmese cat as a genetic model of type 2 diabetes in humans. Anim. Genet. 50, 319-325. https://doi.org/10.1111/age.12799 (2019).

5. Slingerland, L. I., Fazilova, V. V., Plantinga, E. A., Kooistra, H. S. \& Beynen, A. C. Indoor confinement and physical inactivity rather than the proportion of dry food are risk factors in the development of feline type 2 diabetes mellitus. Vet. J. 179, 247-253. https://doi.org/10.1016/j.tvjl.2007.08.035 (2009).

6. Öhlund, M. et al. Environmental risk factors for diabetes mellitus in cats. J. Vet. Intern. Med. 31, 29-35. https://doi.org/10.1111/ jvim.14618 (2017).

7. DIAbetes Genetics Replication And Meta-analysis (DIAGRAM) Consortium. et al. Genome-wide trans-ancestry meta-analysis provides insight into the genetic architecture of type 2 diabetes susceptibility. Nat. Genet. 46, 234-244. https://doi.org/10.1038/ ng.2897 (2014).

8. Xue, A. et al. Genome-wide association analyses identify 143 risk variants and putative regulatory mechanisms for type 2 diabetes. Nat. Commun. 9, 2941. https://doi.org/10.1038/s41467-018-04951-w (2018).

9. Baral, R., Rand, J., Catt, M. \& Farrow, H. Prevalence of feline diabetes mellitus in a feline private practice [abstract]. J. Vet. Intern. Med. 17, 433-434 (2003).

10. McCann, T. M., Simpson, K. E., Shaw, D. J., Butt, J. A. \& Gunn-Moore, D. A. Feline diabetes mellitus in the UK: the prevalence within an insured cat population and a questionnaire-based putative risk factor analysis. J. Feline Med. Surg. 9, 289-299. https:// doi.org/10.1016/j.jfms.2007.02.001 (2007).

11. Lederer, R., Rand, J. S., Jonsson, N. N., Hughes, I. P. \& Morton, J. M. Frequency of feline diabetes mellitus and breed predisposition in domestic cats in Australia. Vet. J. 179, 254-258. https://doi.org/10.1016/j.tvjl.2007.09.019 (2009).

12. Panciera, D. L., Thomas, C. B., Eicker, S. W. \& Atkins, C. E. Epizootiologic patterns of diabetes mellitus in cats: 333 cases (19801986). J. Am. Vet. Med. Assoc. 197, 1504-1508 (1990).

13. Prahl, A., Guptill, L., Glickman, N. W., Tetrick, M. \& Glickman, L. T. Time trends and risk factors for diabetes mellitus in cats presented to veterinary teaching hospitals. J. Feline Med. Surg. 9, 351-358. https://doi.org/10.1016/j.jfms.2007.02.004 (2007).

14. Lipinski, M. J. et al. The ascent of cat breeds: Genetic evaluations of breeds and worldwide random-bred populations. Genomics 91, 12-21. https://doi.org/10.1016/j.ygeno.2007.10.009 (2008).

15. Gandolfi, B. et al. A dominant TRPV4 variant underlies osteochondrodysplasia in Scottish fold cats. Osteoarthr. Cartil. 24, 14411450. https://doi.org/10.1016/j.joca.2016.03.019 (2016).

16. Karlsson, E. K. et al. Genome-wide analyses implicate 33 loci in heritable dog osteosarcoma, including regulatory variants near CDKN2A/B. Genome Biol. 14, R132. https://doi.org/10.1186/gb-2013-14-12-r132 (2013). 
17. King, A. J. F. The use of animal models in diabetes research. Br. J. Pharmacol. 166, 877-894. https://doi.org/10.111 1/j.1476-5381.2012.01911.x (2012)

18. Lyons, L. A. et al. Aristaless-like homeobox protein 1 (ALX1) variant associated with craniofacial structure and frontonasal dysplasia in Burmese cats. Dev. Biol. 409, 451-458. https://doi.org/10.1016/j.ydbio.2015.11.015 (2016).

19. Gandolfi, B. et al. First WNK4-hypokalemia animal model identified by genome-wide association in Burmese cats. PLoS ONE 7, e53173-e53173. https://doi.org/10.1371/journal.pone.0053173 (2012).

20. Kluger, E. K., Caslake, M., Baral, R. M., Malik, R. \& Govendir, M. Preliminary post-prandial studies of Burmese cats with elevated triglyceride concentrations and/or presumed lipid aqueous. J. Feline Med. Surg. 12, 621-630. https://doi.org/10.1016/j. jfms.2010.04.002 (2010).

21. Rusbridge, C. et al. Feline orofacial pain syndrome (FOPS): a retrospective study of 113 cases. J. Feline Med. Surg. 12, 498-508. https://doi.org/10.1016/j.jfms.2010.03.005 (2010).

22. Rand, J. S., Bobbermien, L. M., Hendrikz, J. K. \& Copland, M. Over representation of Burmese cats with diabetes mellitus. Aust. Vet. J. 75, 402-405. https://doi.org/10.1111/j.1751-0813.1997.tb14340.x (1997).

23. Alhaddad, H. et al. Extent of linkage disequilibrium in the domestic cat, Felis silvestris catus, and its breeds. PLoS ONE 8, e53537e53537. https://doi.org/10.1371/journal.pone.0053537 (2013).

24. Gandolfi, B. et al. Applications and efficiencies of the first cat 63K DNA array. Sci. Rep. 8, 7024. https://doi.org/10.1038/s4159 8-018-25438-0 (2018).

25. Aramburu, O. et al. Genomic signatures after five generations of intensive selective breeding: runs of homozygosity and genetic diversity in representative domestic and wild populations of turbot (Scophthalmus maximus). Front. Genet. https://doi.org/10.3389/ fgene.2020.00296 (2020).

26. Gibson, J., Morton, N. E. \& Collins, A. Extended tracts of homozygosity in outbred human populations. Hum. Mol. Genet. 15, 789-795. https://doi.org/10.1093/hmg/ddi493 (2006).

27. Purfield, D. C., McParland, S., Wall, E. \& Berry, D. P. The distribution of runs of homozygosity and selection signatures in six commercial meat sheep breeds. PLoS ONE 12, e0176780-e0176780. https://doi.org/10.1371/journal.pone.0176780 (2017).

28. Metzger, J. et al. Runs of homozygosity reveal signatures of positive selection for reproduction traits in breed and non-breed horses. BMC Genom. 16, 764. https://doi.org/10.1186/s12864-015-1977-3 (2015).

29. Xie, R. et al. Genome-wide scan for runs of homozygosity identifies candidate genes in three pig breeds. Animals (Basel) 9, 518. https://doi.org/10.3390/ani9080518 (2019).

30. Lencz, T. et al. Runs of homozygosity reveal highly penetrant recessive loci in schizophrenia. Proc. Natl. Acad. Sci. 104, 1994219947. https://doi.org/10.1073/pnas.0710021104 (2007).

31. Nalls, M. A. et al. Extended tracts of homozygosity identify novel candidate genes associated with late-onset Alzheimer's disease. Neurogenetics 10, 183-190. https://doi.org/10.1007/s10048-009-0182-4 (2009).

32. Alkuraya, F. S. The application of next-generation sequencing in the autozygosity mapping of human recessive diseases. Hum. Genet. 132, 1197-1211. https://doi.org/10.1007/s00439-013-1344-x (2013).

33. Sams, A. J. \& Boyko, A. R. Fine-scale resolution of runs of homozygosity reveal patterns of inbreeding and substantial overlap with recessive disease genotypes in domestic dogs. G3 Genes Genom. Genet. 9, 117-123. https://doi.org/10.1534/g3.118.200836 (2019).

34. Marsden, C. D. et al. Bottlenecks and selective sweeps during domestication have increased deleterious genetic variation in dogs. Proc. Natl. Acad. Sci. USA 113, 152-157. https://doi.org/10.1073/pnas.1512501113 (2016).

35. Derks, M. F. L. et al. A survey of functional genomic variation in domesticated chickens. Genet. Sel. Evol. 50, 17. https://doi. org/10.1186/s12711-018-0390-1 (2018).

36. Kanai, M., Tanaka, T. \& Okada, Y. Empirical estimation of genome-wide significance thresholds based on the 1000 genomes project data set. J. Hum. Genet. 61, 861-866. https://doi.org/10.1038/jhg.2016.72 (2016).

37. Tian, C., Gregersen, P. K. \& Seldin, M. F. Accounting for ancestry: population substructure and genome-wide association studies. Hum. Mol. Genet. 17, R143-150. https://doi.org/10.1093/hmg/ddn268 (2008).

38. Eu-ahsunthornwattana, J. et al. Comparison of methods to account for relatedness in genome-wide association studies with familybased data. PLoS Genet. 10, e1004445. https://doi.org/10.1371/journal.pgen.1004445 (2014).

39. Meyermans, R., Gorssen, W., Buys, N. \& Janssens, S. How to study runs of homozygosity using PLINK? A guide for analyzing medium density SNP data in livestock and pet species. BMC Genom. 21, 94. https://doi.org/10.1186/s12864-020-6463-x (2020).

40. Ceballos, F. C., Hazelhurst, S. \& Ramsay, M. Assessing runs of Homozygosity: a comparison of SNV array and whole genome sequence low coverage data. BMC Genom. 19, 106-106. https://doi.org/10.1186/s12864-018-4489-0 (2018).

41. Dajani, R. et al. Diabetes mellitus in genetically isolated populations in Jordan: prevalence, awareness, glycemic control, and associated factors. J. Diabetes Complicat. 26, 175-180. https://doi.org/10.1016/j.jdiacomp.2012.03.009 (2012).

42. Saxena, R. et al. Genome-wide association study identifies a novel locus contributing to type 2 diabetes susceptibility in Sikhs of Punjabi origin From India. Diabetes 62, 1746. https://doi.org/10.2337/db12-1077 (2013).

43. Gosadi, I. M., Goyder, E. C. \& Teare, M. D. Investigating the potential effect of consanguinity on type 2 diabetes susceptibility in a Saudi population. Hum. Hered. 77, 197-206. https://doi.org/10.1159/000362447 (2014).

44. Smith, J. M. \& Haigh, J. The hitch-hiking effect of a favourable gene. Genet. Res. 23, 23-35 (1974).

45. Lyons, L. A., Foe, I. T., Rah, H. C. \& Grahn, R. A. Chocolate coated cats: TYRP1 mutations for brown color in domestic cats. Mamm. Genome Off. J. Int. Mamm. Genome Soc. 16, 356-366. https://doi.org/10.1007/s00335-004-2455-4 (2005).

46. Schmidt-Küntzel, A., Eizirik, E., O’Brien, S. J. \& Menotti-Raymond, M. Tyrosinase and tyrosinase related protein 1 alleles specify domestic cat coat color phenotypes of the albino and brown Loci. J. Hered. 96, 289-301. https://doi.org/10.1093/jhered/esi066 (2005).

47. Eizirik, E. et al. Defining and mapping mammalian coat pattern genes: multiple genomic regions implicated in domestic cat stripes and spots. Genetics 184, 267-275. https://doi.org/10.1534/genetics.109.109629 (2010).

48. D’Mello, S. A., Finlay, G. J., Baguley, B. C. \& Askarian-Amiri, M. E. Signaling pathways in melanogenesis. Int. J. Mol. Sci. https:// doi.org/10.3390/ijms17071144 (2016).

49. Acosta, J. L. et al. Rare intronic variants of TCF7L2 arising by selective sweeps in an indigenous population from Mexico. BMC Genet. 17, 68-68. https://doi.org/10.1186/s12863-016-0372-7 (2016).

50. Maedler, K. Beta cells in type 2 diabetes-a crucial contribution to pathogenesis. Diabetes Obes. Metab. 10, 408-420. https://doi. org/10.1111/j.1463-1326.2007.00718.x (2008).

51. Zini, E. et al. Endocrine pancreas in cats with diabetes mellitus. Vet. Pathol. 53, 136-144. https://doi.org/10.1177/0300985815 591078 (2016).

52. Brice, N. L., Varadi, A., Ashcroft, S. J. \& Molnar, E. Metabotropic glutamate and GABA(B) receptors contribute to the modulation of glucose-stimulated insulin secretion in pancreatic beta cells. Diabetologia 45, 242-252. https://doi.org/10.1007/s00125-0010750-0 (2002)

53. Storto, M. et al. Insulin secretion is controlled by mGlu5 metabotropic glutamate receptors. Mol. Pharmacol. 69, 1234-1241. https ://doi.org/10.1124/mol.105.018390 (2006).

54. Yang, C. H. et al. E2f8 and Dlg2 genes have independent effects on impaired insulin secretion associated with hyperglycaemia. Diabetologia 63, 1333-1348. https://doi.org/10.1007/s00125-020-05137-0 (2020).

55. Tsai, F. J. et al. A genome-wide association study identifies susceptibility variants for type 2 diabetes in Han Chinese. PLoS Genet. 6, e1000847. https://doi.org/10.1371/journal.pgen.1000847 (2010). 
56. Chang, Y. C. et al. Replication of genome-wide association signals of type 2 diabetes in Han Chinese in a prospective cohort. Clin. Endocrinol. 76, 365-372. https://doi.org/10.1111/j.1365-2265.2011.04175.x (2012).

57. Vogels, A. \& Fryns, J. P. Age at diagnosis, body mass index and physical morbidity in children and adults with the Prader-Willi syndrome. Genet. Couns. (Geneva, Switzerland) 15, 397-404 (2004).

58. Sinnema, M. et al. Physical health problems in adults with Prader-Willi syndrome. Am. J. Med. Genet. Part A 155a, 2112-2124. https://doi.org/10.1002/ajmg.a.34171 (2011).

59. Stefan, M. et al. Global deficits in development, function, and gene expression in the endocrine pancreas in a deletion mouse model of Prader-Willi syndrome. Am. J. Physiol. Endocrinol. Metab. 300, E909-E922. https://doi.org/10.1152/ajpendo.00185.2010 (2011).

60. Goldstone, A. P., Holland, A. J., Butler, J. V. \& Whittington, J. E. Appetite hormones and the transition to hyperphagia in children with Prader-Willi syndrome. Int. J. Obes. 36, 1564-1570. https://doi.org/10.1038/ijo.2011.274 (2012).

61. Goytain, A., Hines, R. M., El-Husseini, A. \& Quamme, G. A. NIPA1(SPG6), the basis for autosomal dominant form of hereditary spastic paraplegia, encodes a functional Mg2+ transporter. J. Biol. Chem. 282, 8060-8068. https://doi.org/10.1074/jbc.M610314200 (2007).

62. Chan, K. H. K. et al. Genetic variations in magnesium-related ion channels may affect diabetes risk among African American and Hispanic American women. J. Nutr. 145, 418-424. https://doi.org/10.3945/in.114.203489 (2015).

63. Ebert, M. H., Schmidt, D. E., Thompson, T. \& Butler, M. G. Elevated plasma gamma-aminobutyric acid (GABA) levels in individuals with either Prader-Willi syndrome or Angelman syndrome. J. Neuropsychiatry Clin. Neurosci. 9, 75-80. https://doi.org/10.1176/ jnp.9.1.75 (1997)

64. Morris, A. P. et al. Large-scale association analysis provides insights into the genetic architecture and pathophysiology of type 2 diabetes. Nat. Genet. 44, 981-990. https://doi.org/10.1038/ng.2383 (2012).

65. Harder, M. N. et al. Type 2 diabetes risk alleles near BCAR1 and in ANK1 associate with decreased $\beta$-cell function whereas risk alleles near ANKRD55 and GRB14 associate with decreased insulin sensitivity in the Danish Inter99 cohort. J. Clin. Endocrinol. Metab. 98, E801-E806. https://doi.org/10.1210/jc.2012-4169 (2013).

66. Gallagher, P. G. \& Forget, B. G. An alternate promoter directs expression of a truncated, muscle-specific isoform of the human Ankyrin 1 gene. J. Biol. Chem. 273, 1339-1348. https://doi.org/10.1074/jbc.273.3.1339 (1998).

67. Gallagher, P. G., Tse, W. T., Scarpa, A. L., Lux, S. E. \& Forget, B. G. Structure and organization of the human Ankyrin-1 gene: basis for complexity of pre-mRNA Processing. J. Biol. Chem. 272, 19220-19228. https://doi.org/10.1074/jbc.272.31.19220 (1997).

68. Rubtsov, A. M. \& Lopina, O. D. Ankyrins. FEBS Lett. 482, 1-5. https://doi.org/10.1016/s0014-5793(00)01924-4 (2000).

69. Sun, L., Zhang, X., Wang, T., Chen, M. \& Qiao, H. Association of ANK1 variants with new-onset type 2 diabetes in a Han Chinese population from northeast China. Exp. Ther. Med. 14, 3184-3190. https://doi.org/10.3892/etm.2017.4866 (2017).

70. Imamura, M. et al. A single-nucleotide polymorphism in ANK1 is associated with susceptibility to type 2 diabetes in Japanese populations. Hum. Mol. Genet. 21, 3042-3049. https://doi.org/10.1093/hmg/dds113 (2012).

71. Yan, R. et al. A novel type 2 diabetes risk allele increases the promoter activity of the muscle-specific small ankyrin 1 gene. Sci. Rep. 6, 25105. https://doi.org/10.1038/srep25105 (2016).

72. Kline, C. F. et al. Dual role of $\mathrm{K}<\mathrm{sub}>\mathrm{ATP}</ \mathrm{sub}>$ channel C-terminal motif in membrane targeting and metabolic regulation. Proc. Natl. Acad. Sci. 106, 16669-16674. https://doi.org/10.1073/pnas.0907138106 (2009).

73. Aslan, O. et al. Association between promoter polymorphisms in a key cytoskeletal gene (Ankyrin 1) and intramuscular fat and water-holding capacity in porcine muscle. Mol. Biol. Rep. 39, 3903-3914. https://doi.org/10.1007/s11033-011-1169-4 (2012).

74. Chen, J., Ren, J., Loo, W. T. Y., Hao, L. \& Wang, M. Lysyl oxidases expression and histopathological changes of the diabetic rat nephron. Mol. Med. Rep. 17, 2431-2441. https://doi.org/10.3892/mmr.2017.8182 (2018).

75. Subramanian, M. L. et al. Upregulation of lysyl oxidase expression in vitreous of diabetic subjects: implications for diabetic retinopathy. Cells 8, 1122. https://doi.org/10.3390/cells8101122 (2019).

76. Linsenmeier, R. A. et al. Retinal hypoxia in long-term diabetic cats. Invest. Ophthalmol. Vis. Sci. 39, 1647-1657 (1998).

77. Al-Shabrawey, M., Ibrahim, A., Beasley, S., Wang, F. \& Tawfik, A. Bioactive lipids and early inflammatory response in diabetic retinopathy. Acta Ophthalmol. https://doi.org/10.1111/j.1755-3768.2015.0061 (2015).

78. Li, Z. et al. Overexpression of 15-lipoxygenase-1 in oxygen-induced ischemic retinopathy inhibits retinal neovascularization via downregulation of vascular endothelial growth factor-A expression. Mol. Vis. 18, 2847-2859 (2012).

79. Lee, P. et al. Potential predictive biomarkers of obesity in Burmese cats. Vet. J. 195, 221-227. https://doi.org/10.1016/j. tvjl.2012.06.027 (2013).

80. Takada, D. et al. Interaction between the LDL-receptor gene bearing a novel mutation and a variant in the apolipoprotein A-II promoter: molecular study in a 1135-member familial hypercholesterolemia kindred. J. Hum. Genet. 47, 656-664. https://doi. org/10.1007/s100380200101 (2002).

81. Sato, K. et al. Soluble epoxide hydrolase variant (Glu287Arg) modifies plasma total cholesterol and triglyceride phenotype in familial hypercholesterolemia: intrafamilial association study in an eight-generation hyperlipidemic kindred. J. Hum. Genet. 49, 29-34. https://doi.org/10.1007/s10038-003-0103-6 (2004).

82. Ohtoshi, K. et al. Association of soluble epoxide hydrolase gene polymorphism with insulin resistance in type 2 diabetic patients. Biochem. Biophys. Res. Commun. 331, 347-350. https://doi.org/10.1016/j.bbrc.2005.03.171 (2005).

83. Crispin, S. Ocular lipid deposition and hyperlipoproteinaemia. Prog. Retin. Eye Res. 21, 169-224. https://doi.org/10.1016/S1350 -9462(02)00004-6 (2002).

84. Hardman, C. Lipid aqueous as a sign of hyperlipidaemia in Burmese cats. 261 (1999).

85. Kluger, E. K. et al. Triglyceride response following an oral fat tolerance test in Burmese cats, other pedigree cats and domestic crossbred cats. J. Feline Med. Surg. 11, 82-90. https://doi.org/10.1016/j.jfms.2008.05.005 (2009).

86. Ginzinger, D. G. et al. A mutation in the lipoprotein lipase gene is the molecular basis of chylomicronemia in a colony of domestic cats. J. Clin. Investig. 97, 1257-1266. https://doi.org/10.1172/JCI118541 (1996).

87. Camacho, C. et al. BLAST+: architecture and applications. BMC Bioinform. 10, 421. https://doi.org/10.1186/1471-2105-10-421 (2009).

88. Willet, C. E. \& Haase, B. An updated felCat5 SNP manifest for the Illumina Feline 63k SNP genotyping array. Anim. Genet. 45, 614-615. https://doi.org/10.1111/age.12169 (2014).

89. Chang, C. C. et al. Second-generation PLINK: rising to the challenge of larger and richer datasets. GigaScience 4, 7. https://doi. org/10.1186/s13742-015-0047-8 (2015).

90. Kang, H. M. et al. Variance component model to account for sample structure in genome-wide association studies. Nat. Genet. 42, 348-354. https://doi.org/10.1038/ng.548 (2010).

91. Barrett, J. C., Fry, B., Maller, J. \& Daly, M. J. Haploview: analysis and visualization of LD and haplotype maps. Bioinformatics 21, 263-265. https://doi.org/10.1093/bioinformatics/bth457 (2004).

92. Wang, N., Akey, J. M., Zhang, K., Chakraborty, R. \& Jin, L. Distribution of recombination crossovers and the origin of haplotype blocks: the interplay of population history, recombination, and mutation. Am. J. Hum. Genet. 71, 1227-1234. https://doi. org $/ 10.1086 / 344398$ (2002).

93. Li, H. \& Durbin, R. Fast and accurate short read alignment with Burrows-Wheeler transform. Bioinformatics (Oxford, England) 25, 1754-1760. https://doi.org/10.1093/bioinformatics/btp324 (2009). 
94. McKenna, A. et al. The Genome Analysis Toolkit: a MapReduce framework for analyzing next-generation DNA sequencing data. Genome Res. 20, 1297-1303. https://doi.org/10.1101/gr.107524.110 (2010).

95. DePristo, M. A. et al. A framework for variation discovery and genotyping using next-generation DNA sequencing data. Nat. Genet. 43, 491-498. https://doi.org/10.1038/ng.806 (2011).

96. McLaren, W. et al. The Ensembl Variant Effect Predictor. Genome Biol. 17, 122. https://doi.org/10.1186/s13059-016-0974-4 (2016).

97. Ng, P. C. \& Henikoff, S. Predicting deleterious amino acid substitutions. Genome Res. 11, 863-874. https://doi.org/10.1101/gr.17660 $1(2001)$.

\title{
Acknowledgements
}

Funding for this project was provided by Sydney School of Veterinary Science- Constance H. Aird Bequest, Australian Companion Health Fund Ref No.:023/2013 and the Feline Health Research Fund. The authors acknowledge the contributions of Tim Gruffyydd-Jones and Sarah Pierard who provided samples, cat owners and Frank Nicholas for his insightful advice.

\section{Author contributions}

B.H., C.M.W., J.B., and G.S. conceptualised the research and contributed to the progression of overall aims. B.H. and C.M.W. were responsible for the provision of resources. Experimental work, data analysis and visualisation were conducted by G.S. under the supervision of B.H. and C.M.W. Samples were provided by L.A.L., J.B. and L.M.F. Clinical diagnosis was performed by J.B. and L.M.F. The manuscript was written by G.S., all authors read, edited and approved the final manuscript.

\section{Competing interests}

The authors declare no competing interests.

\section{Additional information}

Supplementary information is available for this paper at https://doi.org/10.1038/s41598-020-76166-3.

Correspondence and requests for materials should be addressed to G.S.

Reprints and permissions information is available at www.nature.com/reprints.

Publisher's note Springer Nature remains neutral with regard to jurisdictional claims in published maps and institutional affiliations.

\begin{abstract}
Open Access This article is licensed under a Creative Commons Attribution 4.0 International License, which permits use, sharing, adaptation, distribution and reproduction in any medium or format, as long as you give appropriate credit to the original author(s) and the source, provide a link to the Creative Commons licence, and indicate if changes were made. The images or other third party material in this article are included in the article's Creative Commons licence, unless indicated otherwise in a credit line to the material. If material is not included in the article's Creative Commons licence and your intended use is not permitted by statutory regulation or exceeds the permitted use, you will need to obtain permission directly from the copyright holder. To view a copy of this licence, visit http://creativecommons.org/licenses/by/4.0/.
\end{abstract}

(C) The Author(s) 2021 